\title{
Pituitary-Adrenal Response to Ether Vapor in the Weanling Animal: Characterization of the Inhibitory Effect of Glucocorticoids on Adrenocorticotropin Secretion
}

\author{
DELIA M. VÁZQUEZ AND HUDA AKIL \\ .Mental Health Rescarch Institute /D.M.I'., H.A./ and Department of Pediatrics, Endocrinolog! Division \\ ID.11.1'.J. University of Michigan, Ann Arbor, Michigan 48109
}

\begin{abstract}
The hypothalamic-pituitary-adrenal axis is hyporesponsive to stimuli during early life in the rat. Once the adrenocortical response is established, failure to terminate the corticosterone (B) rise is evident after certain stressors, such as ether. The purpose of this study was 2fold: 1) to investigate the $B$ and $A C T H$ response to ether vapor in young animals and 2) to test the ability of glucocorticoids to inhibit the ether ACTH-stimulated secretion in weanling animals. Rats aged 14, 18, and $25 \mathrm{~d}$ and adult rats were subjected to ether vapor for $3 \mathrm{~min}$. Plasma was collected for B and ACTH determination by RIA at 0,5 , $15,30,60$, and $120 \mathrm{~min}$ after ether exposure. Maximum $B$ levels were observed at different times after exposure: 15 $\mathrm{min}$ in the adult and $30 \mathrm{~min}$ in the younger animals. In addition, $B$ levels were significantly elevated at $60 \mathrm{~min}$ in the $\mathrm{d} 25$ and $\mathrm{d} 18$ rats compared with the adult (d $25=$ $672.4 \pm 28.9$, d $18=744.6 \pm 31.7$, adult $=323.2 \pm 8.7$ $\mathrm{mol} / \mathrm{L} \pm \mathrm{SEM}$; d $25=23.3 \pm 1.0, \mathrm{~d} 18=25.8 \pm 1.1$, adult $=11.2 \pm 0.3 \mu \mathrm{g} / \mathrm{dL} \pm \mathrm{SEM})$. The $B$ delay observed in the younger animals was not due to a delayed $A C T H$ response because maximal ACTII values were observed $5 \mathrm{~min}$ after ether exposure in all ages $(\mathrm{d} 14=21.9 \pm 4.8, \mathrm{~d} 18=35.8$ $\pm 21.3, \mathrm{~d} 25=82.01 \pm 16.5$, adult $=98.9 \pm 25.2 \times 10^{-12}$ $\mathrm{mol} / \mathrm{L} \pm \mathrm{SEM})$. However, in the $\mathrm{d} 25$ rats the $A C I H$ level remained significantly elevated $30 \mathrm{~min}$ after the ether vapor challenge $(5 \mathrm{~min}=86.9 \pm 25.2,30 \mathrm{~min}=61.8 \pm 4.8,60$ $\left.\min =15.3 \pm 4.1 \times 10^{-12} \mathrm{~mol} / \mathrm{L} \pm \mathrm{SENI}\right)$. The delay to return to resting $\mathrm{ACTH}$ levels was consistent with the time delay observed for the $B$ release from the adrenal. However, a rapid increase of plasma steroid achieved with an acute administration of the glucocorticoid cortisol suppresses $A$ CTII release effectively (d $25=74 \%$, adult $=$ $70 \%$ ). Unlike the fast feedback in the adult, the cortisolinduced ACTII inhibition in the weanling animal appears to require a greater cortisol rate of increase (d 25 versus adult $=118.6$ versus $71.73 \mathrm{~mol} / \mathrm{L} / \mathrm{min}, 4.3$ versus $2.6 \mu \mathrm{g} /$ $\mathrm{dL} / \mathrm{min}$ ) and a longer time before basal ACTII levels are achieved (d 25 versus adult $=30$ versus $15 \mathrm{~min}$ ). We conclude that in the weanling rat the inability to rapidly terminate the adrenocortical response after ether vapor results from a combination of adrenal and pituitary and/or brain factors that result in decreased responsiveness to negative feedback even when the rate of steroid is high. Thus, the weaning period represents a distinct phase of the organization of the rat developing stress axis. (Pediatr Res 34: 646-653, 1993)
\end{abstract}

Received March 12. 1993; accepted June 10, 1993.

Supported by NID Grant DA02265 (D.M.V. and H.A.)

Correspondence: Delia M. Vázquez, Mental Health Research Institute, 205 Zina Pitcher Place, Ann Arbor, MI 48109-0720.

\author{
Abbreviations \\ LIIPA, limbic-hypothalamic-pituitary-adrenal \\ CRH, corticotropin releasing hormone \\ SHRP, stress hyporesponsive period \\ $B$, corticosterone \\ F, cortisol \\ ANOVA, analysis of variance \\ MIR, mineralocorticoid receptor \\ GR, glucocorticoid receptor
}

The LHPA axis consists of limbic structures, particularly the hippocampus, modulating the hypothalamic secretagogues, such as $\mathrm{CRH}$ and vasopressin, which in turn control the secretion of ACTH from the anterior pituitary corticotrophs. ACTH stimulates synthesis and secretion of corticosteroids from the adrenal cortex. These potent glucocorticoid hormones then affect numerous functions, including mobilization of energy substrates, increase of cardiovascular tone, and potentiation of the release of catecholamines $(1,2)$. However, prolonged steroid exposure is also linked to detrimental effects such as neuronal death, inhibition of growth, and immune and inflammatory responses $(2,3)$. Therefore, an important component of the LHPA is the glucocorticoid negative feedback that "turns off" the adrenocortical response. This glucocorticoid inhibition is partly achieved by the binding of glucocorticoids to specific cytoplasmic receptors in the hypothalamus and pituitary, where they inhibit CRH and ACTH secretion (4). Additional modulation is exerted by extrahypothalamic sites, especially the hippocampus, which expresses high concentrations of glucocorticoid and mineralocorticoid receptors and has neuronal connections with the hypothalamic CRH neurons (5-7). Thus, the system is intricately controlled via neuronal and hormonal feedback mechanisms to produce optimal responses allowing the organism to deal with various physiologic and environmental events swiftly and adaptively.

Unlike the adult rat, the developing animal appears to have difficulty with both the activation and inhibition of the stress response $(3,8,9)$. Specifically, in the early postnatal period the adrenocortical response is reduced. This SHRP begins on the 2 nd postnatal $d$ and continues until about 2 wk of life (3). The exact duration and the extent of the steroid response varies with the stimuli $(9,10)$. In general, a gradual ACTH and B response to stressors appears after $\mathrm{d} 10$ and is well established to an adult level by weaning age (21-25 d old) (3). Once the activation of the system is considered operational, the glucocorticoid negative feedback regulation is described as immature to certain stressors. For example, Goldman et al. (8) have shown that, compared 
with the adult animal, the weanling animal has a late, robust $B$ peak but a slower return to resting $B$ levels after exposure to ether vapor and foot shock. This has led to the notion that, in the weanling animal, the glucocorticoid suppression of the LHPA axis remains immature and continues to develop during the postweaning period $(3,8)$. If this notion is correct, it then becomes important to test in the developing animal the adequacy of those key elements that have proven to be essential for the rapid inhibition of $A C T H$ secretion by $B$ in the adult rat.

Studies performed in the adult rat conclude that B suppression of ACTH secretion is divided in at least three time domains: fast. intermediate, and delayed. Fast feedback occurs withir. $30 \mathrm{~min}$ of the stress; intermediate and delayed feedback are evident over a longer time frame. hours to days. Fast feedback is unique in that it occurs immediately during periods of increasing $B$ concentration (11), only with 21 -hydroxyl and $11-\beta$-hydroxyl steroid groups $(B$ and $F)(12,13)$, and the effect is on stimulated $C R H$ and $A C T H$ release rather than biosynthesis of these peptides (11, 14). It has been suggested that the mechanism by which fast feedback operates may be linked to hippocampal neurons leading to the hypothalamus. These neurons are rich in glucocorticoid and mineralocorticoid receptors (both of which bind $B$ ), and removal of the hippocampal structure (15) or the reduction of $B$ binding sites $(5,16-18)$ results in an increased LHPA activity and $B$ hypersecretion.

B hypersecretion in the weanling animal, seen after the exposure to ether vapor, supports the notion of an impaired fast feedback mechanism. However, Goldman ( $t$ al. (8) did not measure plasma ACTH levels and did not assess the B inhibition of pituitary ACTH directly. Therefore, only indirect evidence of an impaired fast feedback after ether stress is present in this age group. Greater detail of the pituitary and adrenal response is necessary before an understanding of the underlying impairment in the feedback mechanism is pursued. In the present study, we sought direct evidence for an immature negative feedback inhibition in the weanling animal after exposure to ether vapor. For this purpose, we compared the ACTH and B response to ether vapor in the developing weanling and adult animal. Specifically, we addressed the following questions: $l$ ) Does a delayed ACTH response explain the late $B$ peak and subsequent elevated levels in the weanling animal? 2) Is the 25-d-old animal adrenocortical response unable to inhibit ACTH secretion once the ether stress response is initiated? and 3 ) If the latter is true, does exogenous administration of a glucocorticoid inhibit the ACTH response to ether stress in the weanling animal? The results suggest that after ether exposure a delayed response occurs at the adrenal level and the prolonged $B$ elevation can, in part, be explained by a sustained ACTH response and by adrenal factors. When the adrenal factors are eliminated by the administration of glucocorticoids before ether exposure, ACTH secretion is suppressed. However, this suppression is less efficient than that which is achieved by the adult animal.

\section{MATERIALS AND METHODS}

Animals. Sprague-Dawley female rats (Charles River, Wilmington, $\mathrm{M} \Lambda$ ) were mated in our animal unit. Animals are maintained in accordance with the NIH Guidelines for the Care and Use of Laboratory' Animals. Pregnant rats had free access to food and water and were kept on a $14 \mathrm{~h}$ light, $10 \mathrm{~h}$ dark cycle. Vaginal plugs marked the first day of pregnancy. On the day of delivery, which was considered d 1 of life, the litters were reduced to 12 pups and were left undisturbed until the day of experimentation. Those pups that were going to be used as the 25-d-old experimental and control groups were removed from their mother on d 21 of life and grouped six animals per home cage. Adult males ( $65 \mathrm{~d}$ old) were also obtained from our breeding facilities and from Charles River. In an initial pilot experiment, adult animals bred in our facilities and animals obtained directly from the vendor and allowed to rest for 2 wk were exposed to ether vapor. $A C T H$ and $B$ responses from these two animal sources were compared and were found to have identical $B$ profiles. The ACTH inhibition by $F$ was also found to be similar. Therefore, adult males obtained from Charles River were used for comparison in all experiments. They were allowed to rest for $2 \mathrm{wk}$ before the experiment and were housed three animals per home cage with free access to food and water. All experiments were carried out in the morning, between 0800 and $1100 \mathrm{~h}$.

Studies. Pituitary and adrenocortical response to ether vapor. Animals aged 14, 18, and $25 \mathrm{~d}$ were removed from their home cage in groups of six (as they were housed in groups of six) and adults were removed in groups of three (as they were housed in groups of three). They were transferred to an adjacent experimental room and were immediately placed in a glass jar containing gauzes saturated with ether below a wire mesh platform. The animals were maintained in the closed container for $3 \mathrm{~min}$, sufficient time to anesthetize all the animals in the jar (six young animals or three adult animals). They were then returned to a plastic cage, similar to their home cage, where the pups were mixed to randomize the litters for each time point studied. All animals were killed by rapid decapitation at $5,15,30,60$, or 120 min after being placed in the container. Trunk blood was collected in chilled tubes containing EDTA for subsequent plasma $\mathrm{B}$ and $\mathrm{ACTH}$ determination. In addition. eight previously unhandled animals of each age were also killed for an estimation of resting $A C T H$ and $B$ levels (time 0 min control group). Six animals of each age were sampled for every other time point.

A second experiment was performed in 25-d-old animals under the same conditions as above; however, the 25-d-old animals were killed $5,10,15,30,40,50,60$, and $120 \mathrm{~min}$ after ether exposure. Trunk blood was collected as before in EDTA-containing tubes for plasma ACTH determination. Six animals of each age were sampled at each time point. Eight unhandled animals were also killed to estimate basal ACTH and B level (control group).

Glucocorticoid effect on pituitary response to ether vapor. The ability of glucocorticoids to inhibit pituitary ACTH secretion in 25-d-old and adult rats was tested by administering $F$ solution intraperitoneally at the onset of a 3-min exposure to ether vapor. In an initial pilot experiment, two $\mathrm{F}$ doses were tested in adult animals: $0.030 \mathrm{mg} / \mathrm{kg}$ of body weight and $0.060 \mathrm{mg} / \mathrm{kg}$ body weight. The $\mathrm{F}$ dose that caused greater than $50 \%$ inhibition of ACTH secretion was selected for subsequent experiments. Therefore, 25-d-old and adult rats were tested by administering cortisol solution $0.060 \mathrm{mg} / \mathrm{kg}$ body weight intraperitoneally at the onset of a 3 -min exposure to ether vapor $(0.2 \mathrm{~mL}$ per animal). Salineinjected animals were used as controls. Animals were killed by decapitation at $5,15,30,40,60$, or $120 \mathrm{~min}$ after being placed in the closed ether-containing glass jar. Trunk blood was collected in EDTA-containing tubes for plasma $F, B$, and ACTH determination. Six animals of each age were sampled at each time point. Eight previously unhandled animals of each age were also killed for an estimation of resting ACTH and B levels (control group). Two experiments were performed for the 25-d-old age group.

Plasma Assays. Plasma ACTH assay: Plasma ACTH is measured by RIA, which has been described in previous reports ( 19 . 20). The assay uses $\mathrm{ACTH}_{1-24}$ as standard and a specific rabbit antibody that recognizes the middle portion of $\mathrm{ACTH}$ (a generous gift of the late Fernando Estivariz, La Plata, Argentina). It is used at a final concentration of 1:20 000. The antibody crossreacts less than $1 \%$ with $\alpha$ melanocyte stimulating hormone and desacetyl melanocyte stimulating hormone and has no crossreactivity with $\mathrm{ACTH}_{17-34}$ (corticotrophin-like intermediate lobe peptide). The radioligand is mono 3-[25 I-iodotyrosyl $\left.{ }^{23}\right]$ $\mathrm{ACTH}_{1-39}$ (New England Nuclear. Boston, MA $50 \mathrm{Ci} / \mathrm{mmol}$ ). and a $1 \%$ charcoal $/ 0.1 \%$ dextran $/ 10 \%$ normal rabbit serum mixture is used for the separation of the bound and unbound phase. The detection limit is $1 \times 10^{-12} \mathrm{~mol} / \mathrm{L}(1 \mathrm{fmol} / \mathrm{mL}, 4.541$ 
$\mathrm{pg} / \mathrm{mL}$ ) (intraassay coefficient of variation $\pm 2 \%$, interassay coefficient of variation $\pm 3 \%$ ).

Plasma B assay. Plasma B is measured by RIA using a method adapted from West $c t$ al. (21). It uses a specific rabbit antibody (B3), a generous gift of the late Fernando Estivariz at a final concentration of $1: 4000$. The antibody cross-reacts $2.2 \%$ with $F$ and less than $1 \%$ with other endogenous steroids. The radioligand is ${ }^{3} \mathrm{H}-\mathrm{B}$ (Amersham $50 \mathrm{Ci} / \mathrm{mmol}$ ), and $1 \%$ charcoal $/ 0.1 \%$ dextran mixture is used for the separation of the bound and unbound phase. The detection limit is $4.5 \times 10^{-8} \mathrm{~mol} / \mathrm{L}$ (molecular weight $=346.47$; detection limit is $1 \mathrm{pg} / \mathrm{mL}$ ) (intraassay coefficient of variation $\pm 3 \%$, interassay coefficient of variation $\pm 2 \%$ ).

Plasma cortisol assay. Plasma cortisol is measured by RIA using a "Coat-A-Count" RIA kit from Diagnostic Products Corporation (Los Angeles, CA). The kit is designed for the quantitative measurement of human samples using human serumbased standard F concentrations. Therefore, the assay is modified for rat samples using adrenalectomized rat serum with known $\mathrm{F}$ concentrations. Under these conditions, $100 \%$ of the plasma cortisol and $1.4 \%$ of plasma $\mathrm{B}$ are detected. The detection limit is $5.5 \times 10^{-9} \mathrm{~mol} / \mathrm{L}$ (molecular weight $=362.47$; detection limit is $0.2 \mu \mathrm{g} / \mathrm{dL}$ ) (intraassay coefficient of variation $\pm 2 \%$, interassay coefficient of variation $\pm 5 \%$ ).

Statistical Analysis. A two-factor ANOVA and two-factor repeated measure ANOVA were used for the analysis of age and time interactions. Post hoc comparisons of sex and treatment group differences were made with Fisher protected least significant difference (22). Because sex differences were not present, sex was not considered a variable for the statistical analysis. In addition, $t$ test was performed to compare the ACTH response of adult and 25-d-old animals to ether vapor after administration of $F$. Values are expressed as mean \pm SEM.

\section{RESULTS}

Response to ether vapor. The adrenocortical response to ether vapor of the 14-, 18-, and 25-d-old animals is compared with that of the adult animal in Figure 1. The adult animal had its maximal $B$ release $15 \mathrm{~min}$ after the exposure to ether vapor. All younger animals had a delayed $B$ release. Their maximal release was observed at $30 \mathrm{~min}$, a 15 -min delay compared with the adult adrenal response. Note that the 14-d-old animal had a dampened $B$ response to ether with a peak effect substantially lower than all other groups. However, the 14-d-old animal maintained a sustained $B$ release relative to its peak value at $60 \mathrm{~min}(30 \mathrm{~min}$ $=100 \%$ release; $60 \mathrm{~min}=85 \%$ of peak $\mathrm{B}$ level). Thus, although only the 18- and 25-d-old animals show significantly elevated B values at 60 min compared with the adult 60 -min time point $(F$ $=3.8, p=0.03$ ), the 14-d-old animal also showed a significant $B$ release and failure to return to basal levels at this time point $(F=15.6, p=0.0001)$. Overall, a two-factor ANOVA revealed an age effect $(F=14.5 ; p=0.0001)$, an effect of time after ether

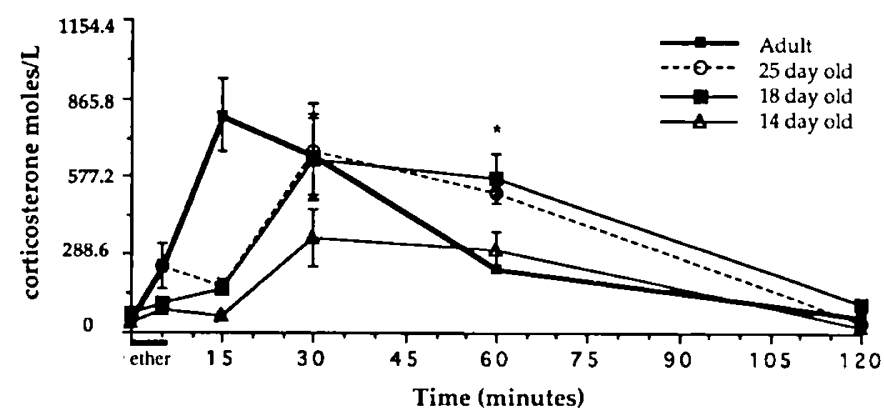

Fig. 1. Time course of the plasma B secretion after a 3-min exposure to ether vapor. Twenty-five-, 18-, and 14-d-old animals' responses are compared with the adult response. Values are the mean \pm SEM of six animals per time point. ${ }^{*}, p \leq 0.001$, time 0 is time marked. One $\mu \mathrm{g} / \mathrm{dL}$ $\mathrm{B}=28.86 \mathrm{~mol} / \mathrm{L}$.
$(F=22.9 ; p=0.0001)$, and an interaction between time and age $(F=5.8 ; p=0.0001)$.

The pituitary response to ether vapor was assessed by measuring plasma ACTH levels from these same animals (Fig. 2). Peak ACTH levels were observed in all ages $5 \mathrm{~min}$ after exposure to ether vapor. The extent of the pituitary response differed across ages. The 14- and 18-d-old animals showed a significantly reduced $\mathrm{ACTH}$ release compared with the 25-d-old and adult animals $(F=8.8 ; p=0.0001)$. Note, however, that in spite of the reduced $\mathrm{ACTH}$ release in the 18-d-old animal, the $\mathrm{B}$ response was comparable to that of the 25-d-old (Figs. 1 and 2).

Although the 25-d-old rat had a maximal ACTH response equivalent to that of the adult animal, the ACTH level remained significantly elevated for a longer period of time. This effect was also seen in the younger animals, which show significantly elevated ACTH values compared with their baseline (Fig. 2, $F=$ $8.2 ; p=0.003$ by two-factor repeated measure ANOVA). In fact, the ACTH level was elevated 15 min longer in 25 -d-old animal compared with the adult (Fig. 2). The delay to return to resting ACTH level paralleled the time delay observed for the $B$ release from the adrenal gland, i.e. $30 \mathrm{~min}$ (Fig. 3). It can also be seen in Figure 3 that although the increase in B plasma concentrations led to the decrease in plasma ACTH levels in both the adult and 25 -d-old animals, the calculated rate of B increase that is observed in the adult is twice the rate of the 25-d-old animal (Table 1 , ether vapor for adult and 25-d-old). This increased rate of increase in the adult animal appears to translate into a steeper and quicker decline of ACTH levels.

Glucocorticoid effect on pituitary response to ether vapor. In view of the fact that the delayed adrenal response to ether may be contributing to the pattern of $\mathrm{ACTH}$ release and decline in the 25-d-old animal, F was administered to adult animals and 25-d-old animals immediately before ether exposure. A $50 \%$ or greater ACTH inhibition was defined as an effective glucocorticoid feedback inhibition. $F$ administration before the exposure to ether vapor resulted in an equivalent blunting of the ACTH response in both the adult and 25-d-old animals (Figs. $4 A$ and $B$ and $5 A$ and $B$ ). The adult animal showed an ACTH decrease of $70 \%$ (Table $1 ; F=3.84, p<0.05$ ). Similarly, the 25 -d-old animal had a $74 \%$ ACTH decrease (Table 1: $F=3.84, p<0.05$ ). Even though the $A C T H$ suppression after $F$ administration was similar, the 25-d-old animal had a significant transient ACTH response to ether vapor compared with the adult $(p<0.05, t$ test $)$. Notice also that the degree of inhibition was quicker in the adult animal compared with the 25 -d-old animal $(15$ min versus 30 min; Figs. 4 and $5 B$ ). This is more evident when the plasma $F$ levels are considered (Figs. $4 A$ and $B$ and $5 A$ and $B$ ). Despite an equivalent $F$ dose per body weight $(0.060 \mathrm{mg} / \mathrm{kg})$, it can be seen that the plasma $F$ levels increased at a greater rate and to a greater extent in the 25-d-old animal (Figs. $4 A$ and 5.1 , Table 1), yet the ACTH response persisted, to a limited extent, for $30 \mathrm{~min}$.

The adrenal response was also assessed in the 25 -d-old and adult animals treated with $\mathrm{F}$ before ether exposure (Figs. $4 C$ and $5 C$ ). The adult animal had a suppression of $B$ release until 30 min after the stressor when plasma ACTH levels start to rise (Fig. $4 B$ and $C$. Table 1). Although there was a markedly blunted pituitary ACTH response to ether vapor in the 25-d-old animal treated with cortisol before the ether exposure, an adrenocortical response was observed by $30 \mathrm{~min}$ (Fig. $4 B$ and $C$, Table 1).

\section{DISCUSSION}

The present study made use of simultaneous plasma ACTH and $B$ measures to investigate the response to ether vapor in the developing and weanling animal. In addition, we investigated the effectiveness of rising plasma glucocorticoid levels in suppressing the ether-activated ACTH secretion in the 25-d-old animal. We found that in the weanling rat the inability to rapidly terminate the adrenocortical response after ether vapor results from a combination of adrenal factors leading to a slow $B$ rate 


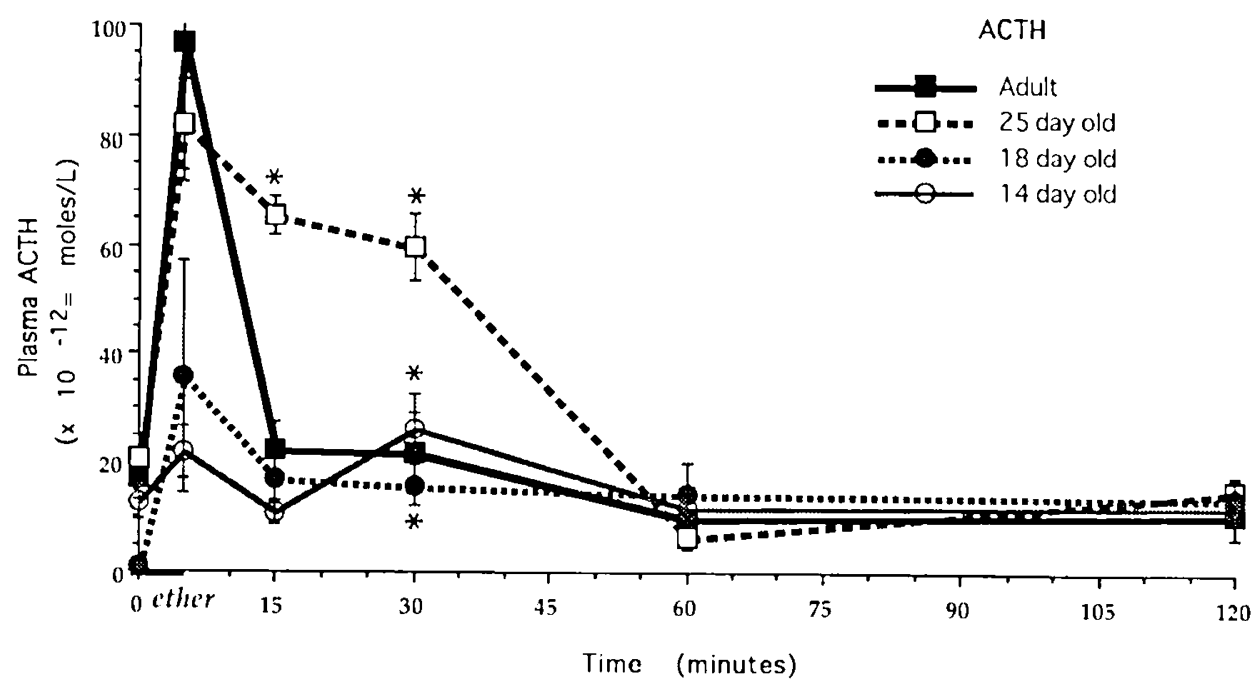

Fig. 2. Time course of the plasma ACTH secretion after a 3-min exposure to ether vapor. Twenty-five-, 18-, and 14-d-old animals' responses are compared to the adult response. Values are the mean \pm SEM of six animals per time point. ${ }^{*}, p \leq 0.001$, time () vis time marked.

A.

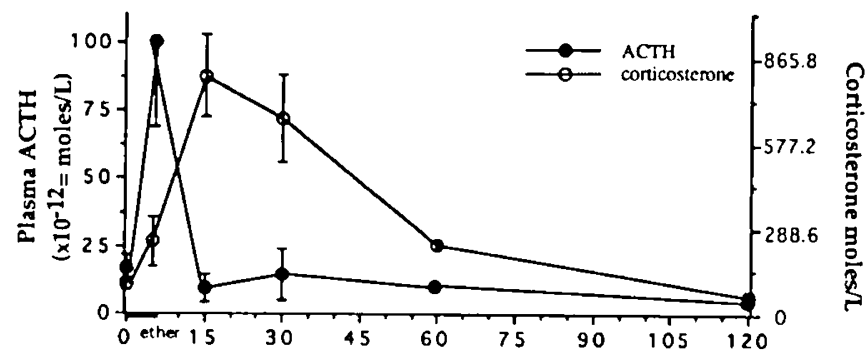

B.

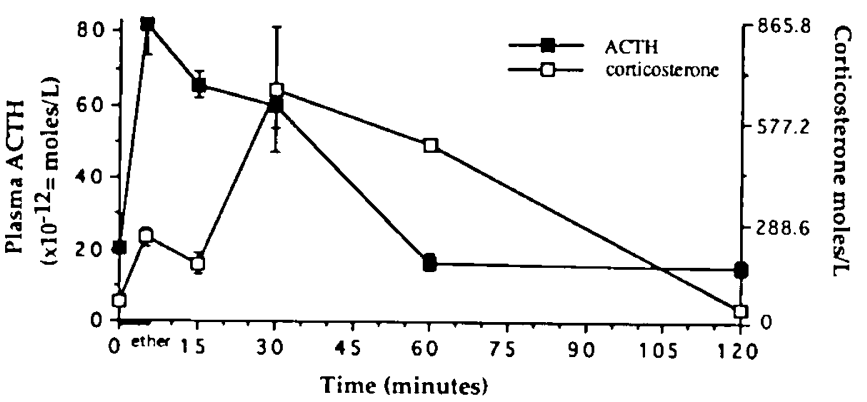

Fig. 3. Plasma $B$ and $A C T H$ concomitant relationships in the adult $(A)$ and $25-\mathrm{d}-\mathrm{old}(B)$ animal. The data are a composite of data illustrated in Figures 1 and 2 . One $\mu \mathrm{g} / \mathrm{dL} \mathrm{B}=28.86 \mathrm{~mol} / \mathrm{L}$.

of increase and pituitary and/or brain development factors that result in decreased responsiveness to negative feedback even when the rate of glucocorticosteroid is high.

Before the current study, it had been suggested that fast feedback glucocorticoid inhibition may be immature in the weanling animal, based primarily on prolonged $\mathrm{B}$ response to ether vapor (8). Our B data replicate these previous studies, which showed an initial delay of the B release and an elevation of levels $60 \mathrm{~min}$ after ether. However, the ACTH response to ether shows that the 25-d-old animal has a unique pituitary response: therefore, both the adrenal and pituitary components need to be viewed separately and in combination. Specifically, the ACTH response to ether vapor is rapid and of the same magnitude as in the adult animal. In contrast, the adrenal has a slow activation and a delayed, slow increase of plasma B levels. The result is a decreased fast or "rate-dependent" negative feedback that is evidenced by a sustained ACTH secretion followed by a prolonged B response. However, if the adrenal's overall delayed response to ACTH levels is improved by using glucocorticoid administration, an effective ACTH inhibition appears to take place. However, qualitative differences between the adult mature fast feedback mechanism and that of the 25-d-old animal are indeed present. It is evident that both adrenal and supraadrenal elements of the hypothalamic-pituitary-adrenal axis in the 25-d-old animal contribute to a less than perfect fast feedback response.

The activation of the LHPA axis by ether vapor in the developing animal is prompt, but the adrenal has a slow response. The LHPA system of the 14-, 18-, and 25-d-old animals is clearly capable of responding to ether vapor. The response at all ages is rapid, not unlike that of the adult animal, which has a peak ACTH response $5 \mathrm{~min}$ after the onset of stress. The ACTH response of the 14-d-old animal is peculiar in that it is lower compared with later ages and exhibits a biphasic pattern at 5 $\mathrm{min}$ and $30 \mathrm{~min}$ after the onset of stress. This reduced response and biphasic ACTH pattern is similar to that observed in 5- and 10 -d-old animals who are exposed to ether vapor (9) and may in fact, reflect limitations at these ages of both the pituitary and hypothalamic level of the LHPA axis. Several coinciding events during this period may explain these specific limitations. The expression of both proopiomclanocortin and CRH genes, in the pituitary and paraventricular nucleus of the hypothalamus respectively, is reduced during the first week of life (23). Hypothalamic arginine vasopressin expression also has a gradual increase after birth and reaches $40 \%$ of the adult levels after the 2 nd postnatal wk of life (24). Moreover, the neuronal circuits, which may be important for stimulation and secretion of $\mathrm{CRH}$ and arginine vasopressin, are not completely established during this time (25-29). In particular, catecholaminergic innervation of hypothalamic paraventricular neurons occurs progressively during the $1 \mathrm{st}$ wk of life and its steepest rise takes place between $d$ 7 and 14 , after which an adult innervation is established (26). A similar increase of $\alpha$ and $\beta$ brain adrenergic receptors is observed during the 2 nd wk of life $(30,31)$. This developmental progression is consistent with our finding that the magnitude of the $\mathrm{ACTH}$ response to ether increases steadily with age and is equivalent to the adult response in the 25-d-old animal. Interestingly, the elevated response is sustained in the 25 -d-old animal and follows a pattern of pituitary inhibition that parallels adrenal response.

The adrenal of developing rats differs from that of the adult animal in that it responds with a specific time course that varies 
Table 1. Total ACTII response and glucocorticoid relationships in the adult, 25-d-old, and IS-d-old animals*

\begin{tabular}{|c|c|c|c|c|c|c|c|}
\hline & \multirow{2}{*}{$\begin{array}{c}\text { Total ACTH } \\
\text { response } \dagger \\
\left(\times 10^{-12}=\mathrm{mol} / \mathrm{L}\right)\end{array}$} & \multicolumn{2}{|c|}{$\begin{array}{l}\text { Adrenal B response per } \\
\text { fmol ACTH released } \neq\end{array}$} & \multicolumn{2}{|c|}{ B rate of increase } & \multicolumn{2}{|c|}{$F$ rate of increase } \\
\hline & & $\mathrm{mol} / \mathrm{L}$ & $\mu \mathrm{g} / \mathrm{dL}$ & $\mathrm{mol} / \mathrm{L} / \mathrm{min}$ & $\mu \mathrm{g} / \mathrm{dL} / \min$ & $\mathrm{mol} / \mathrm{L} / \mathrm{min}$ & $\mu \mathrm{g} / \mathrm{dL} / \mathrm{min}$ \\
\hline \multicolumn{8}{|l|}{ Adult } \\
\hline Ether vapor & $168.3 \pm 8.9$ & $8.4 \pm 37.5$ & $0.29 \pm 1.3$ & $69.3 \pm 2.9 \$$ & $2.4 \pm 0.1 \$$ & & \\
\hline Cortisol + ether vapor & $50.2 \pm 7.3$ & $1.1 \pm 28.9$ & $0.04 \pm 1.0$ & $5.72 \pm 2.9 \$$ & $0.2 \pm 0.1 \$$ & $71.7 \pm 2.7 \|$ & $2.6 \pm 0.1 \|$ \\
\hline \multicolumn{8}{|l|}{ 25-d-old } \\
\hline Ether vapor & $295.0 \pm 3.6$ & $6.9 \pm 57.7$ & $0.24 \pm 2.0$ & $34.6 \pm 2.9 \S$ & $1.2 \pm 0.1 \$$ & & \\
\hline Cortisol + ether vapor & $75.5 \pm 29$ & $24.5 \pm 89.5$ & $0.85 \pm 3.1$ & $37.5 \pm 2.9^{* *}$ & $1.3 \pm 0.1^{* *}$ & $\begin{array}{l}126.6 \pm 2.7 \| \\
118.3 \pm 2.7 \$\end{array}$ & $\begin{array}{l}4.6 \pm 0.1 \| \\
4.3 \pm 0.1 \$\end{array}$ \\
\hline $\begin{array}{l}\text { 18-d-old } \\
\text { Ether vapor }\end{array}$ & $53.8 \pm 8.6$ & $15.6 \pm 28.9$ & $0.54 \pm 1.0$ & $26.0 \pm 2.9 \$$ & $0.9 \pm 0.05 \$$ & & \\
\hline
\end{tabular}

* One $\mu \mathrm{g} / \mathrm{dL} \mathrm{B}=28.86 \mathrm{~mol} / \mathrm{L} ; 1 \mu \mathrm{g} / \mathrm{dL} \mathrm{F}=27.59 \mathrm{~mol} / \mathrm{L}$. Values are mean $\pm \mathrm{SEM}$.

† Hormonal response calculated by adding all the values that constitute a peak.

$\$$ Peak $\mathrm{B}$ response to ether vapors $\div$ ACTH peak response.

$\S$ Rate of increase over $15 \mathrm{~min}$.

\| Rate of increase over $5 \mathrm{~min}$.

I Cortisol + ether vapor: adult $v$ is 25 -d-old, $p<0.05$ by $t$ test.

** Rate of increase over $30 \mathrm{~min}$.

with age and the specific stressor (9). Overall, the developing adrenal has a delayed $B$ response regardless of the stressor. This appears to be consistent even with potent stressors, such as hypoglycemia. For example, the 24 -h-old pup has a robust B secretion $60-90 \mathrm{~min}$ after insulin administration $(721.5 \mathrm{~mol} / \mathrm{L}$; $25 \mu \mathrm{g} / \mathrm{dL}$ peak B level) (32). A similar adrenocortical delay is observed in the 10-d-old animal in which B secretion increases to a peak level $60 \mathrm{~min}$ after histamine administration (peak B level of $115.44 \mathrm{~mol} / \mathrm{L} ; 4 \mu \mathrm{g} / \mathrm{dL}$ ) (9). Ether vapor, on the other hand, provokes a small $B$ response between 15 and 60 min after exposure in the 10-d-old animal (9). Goldman et al. (8) found that in the 25 -d-old animal a peak $B$ response equivalent to that of the adult is observed at $30 \mathrm{~min}$ after ether vapor. In contrast, the adult B peak is observed 15 min after ether exposure (8). Our data are consistent with these findings in all ages tested, i.e. 14-, $18-$, and 25 -d-old animals. As predicted by others $(3,9)$, the adrenal $B$ release progresses to a peak adult response as the animal matures and leaves the SHRP. However, our data also support the notion that once the SHRP is surpassed, ether vapor continues to cause a slow adrenal activation and delayed $B$ response prevails in the weanling animal.

Histologic and cytochemical studies performed on the developing rat adrenal cortex suggest a morphologic basis for the sluggish adrenal response. Morphologic changes in the developing adrenal cortex include organization of cellular zones, increasing cell number, and increasing number and size of the cytoplasmic lipid vacuoles characteristic of steroid-producing cells $(33,34)$. At birth, only the two cortical zones responsible for mineralocorticoid and glucocorticoid steroid synthesis are anatomically evident: the glomerulosa and fasciculata. Gradually, the glomerulosa organizes into round balls and arcs that are characteristic of this adult cortical zone. Mitotic figures are frequent in glands up to $4 \mathrm{wk}$ of age and disappear in 6-wk-old animals. Similarly, cytochemical staining and birefringence, which are characteristic of steroid-producing cells, also increase markedly at $4 \mathrm{wk}$ of age (35). Small lipid droplets present at birth suggest that the adrenocortical response to stress is rapid at this time. Indeed, neonatal rats, up to $2 \mathrm{~d}$ old, have a rapid $\mathrm{B}$ rise after numerous stressors, including ether vapor $(3,9,32)$. A delay in $B$ release is observed after age $5 \mathrm{~d}$. Larger droplets aild greater crystal density are present up to $4 \mathrm{wk}$ of age, which correlate with the delayed $B$ response to stressors that is found after $5 \mathrm{~d}$ of age and is evident in our own observations of the 25-d-old animal exposed to ether vapor. It is also possible that the ether vapor is noxious to the developing adrenal, thus resulting in longer latency to respond to ACTH compared with the adult animal. However, it is important to note that a delayed adrenocortical response is also evident with other stressors (e.g. histamine), as described above. Therefore, it appears that a major component of the adrenal refractoriness to ACTH stimulation observed in the 25-d-old animal may be intrinsic developmental factors unique to the maturation of the adrenal.

Termination of the adrenal response is unique in the developing and weanling animal. After the peak B response to ether vapor, the 14-, 18-, and 25-d-old rats' corticosterone levels remained elevated well beyond the time in which $B$ levels decline in the adult animal, i.e. $60 \mathrm{~min}$. The metabolic clearance of B may be a contributing factor to the elevated $B$ levels observed at this time. To evaluate this possibility, the B levels were first normalized across ages as a percent of the maximal $\mathrm{B}$ response. Then, the time required for plasma to decrease to $50 \%$ of the maximal steroid response was determined. After comparing these results with the $t_{1 / 2}$ of plasma $B$ obtained by kinetics studies in which ${ }^{3} \mathrm{H}$-corticosterone was administered i.v. and the rate of disappearance from plasma was evaluated in rats of different ages (36-40), it was evident that metabolic clearance does not account for the elevated $B$ levels found in the animals exposed to ether vapor. Rather, the elevated and sustained nature of the ACTH release observed in the 25-d-old animal appears to predict the elevated plasma $B$ levels at $60 \mathrm{~min}$. This finding alone would point to an impaired fast feedback mechanism, but because fast feedback is dependent on the adrenocortical response to ACTH, one must consider the delayed adrenal activation and the resulting B rate of increase before reaching this conclusion.

Fast feedback is, by definition, a rate-sensitive, rapid inhibitory effect on ACTH secretion that occurs as plasma B levels are increasing $(11,15,41)$. The degree of inhibition is proportional to the rate of plasma B increase. A rate of at least $1.3 \mu \mathrm{g} / \mathrm{dL} / \mathrm{min}$ $(37.5 \mathrm{~mol} / \mathrm{L} / \mathrm{min})$ is necessary for rapid inhibition in male rats under surgical stress (11). Higher levels $(4-6 \mu \mathrm{g} / \mathrm{dL} / \mathrm{min} ; 115.4-$ $173.2 \mathrm{~mol} / \mathrm{L} / \mathrm{min}$ ) are necessary in females, presumedly because of a higher proportion of bound B compared with males (11, 15). In our study, a rate of $B$ increase equivalent to $2.4 \mu \mathrm{g} / \mathrm{dL} /$ $\min (69.3 \mathrm{~mol} / \mathrm{L} / \mathrm{min})$ was sufficient to cause immediate ACTH inhibition to basal levels in the adult animals. The 25-d-old animal also has ACTH suppression as B rises at a rate of $1.2 \mu \mathrm{g} /$ $\mathrm{dL} / \mathrm{min}(34.6 \mathrm{~mol} / \mathrm{L} / \mathrm{min})$. Unlike the adult, which has a rapid $\mathrm{B}$ rise during the first $15 \mathrm{~min}$ after ether exposure, the 25 -d-old animal's B rise occurs between 15 and $30 \mathrm{~min}$ due to the delayed adrenal response. Although the rate of $B$ increase is very close to the rate that has been shown to suppress ACTH secretion in the adult, it is evident that the 25-d-old animal has a slower decline of ACTH levels compared with the mature animal.

Is the delayed response of the adrenal partially responsible for 
A.

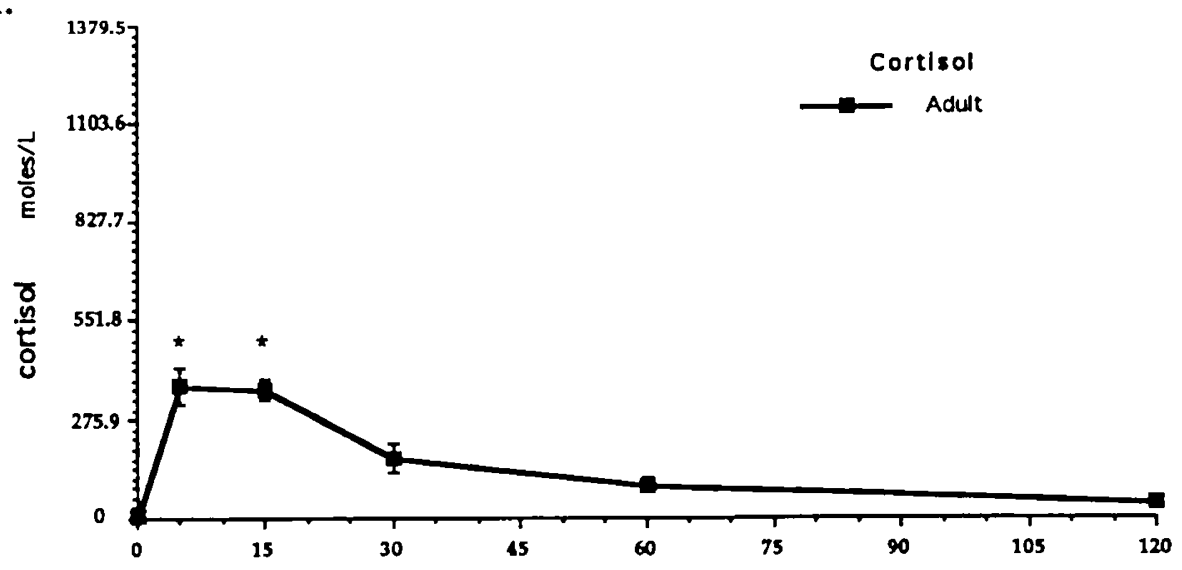

B.

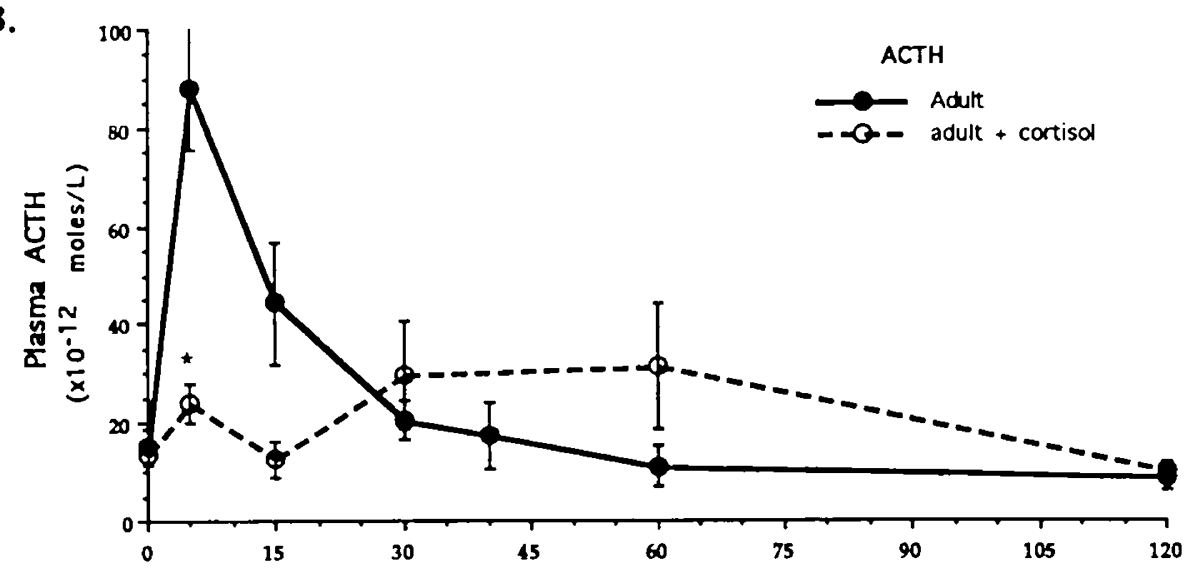

C.

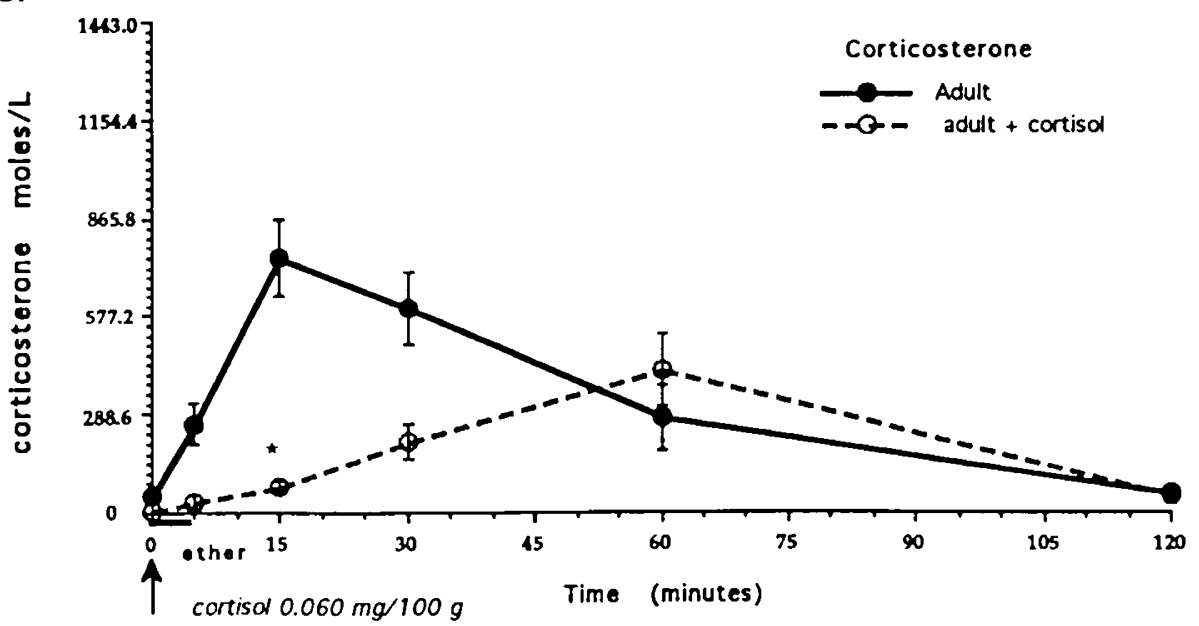

Fig. 4. The response of adult animals treated with $0.060 \mathrm{mg} / 100 \mathrm{~g}$ body weight of $\mathrm{F}$ intraperitoneally at the onset of a $3-\mathrm{min}$ ether vapor exposure. $A$ depicts plasma F levels. $B$ shows the ACTH response, and $C$ the B response of animals treated with saline $(\bullet)$ vs $F(O)$. ${ }^{*}, p \leq 0.001, F$ treatment is ether response. One $\mu \mathrm{g} / \mathrm{dL} \mathrm{B}=28.86 \mathrm{~mol} / \mathrm{L}: 1 \mu \mathrm{g} / \mathrm{dL} \mathrm{F}=27.59 \mathrm{~mol} / \mathrm{L}$.

the sustained ACTH levels and the delay of its decline? To clarify the role of the adrenal on the slow decline of ACTH levels in the weanling animal, $F$ was administered at the onset of the ether challenge. $F$ was the chosen glucocorticoid for several reasons. $F$ levels achieved are readily measurable, yet $F$ allows for the assessment of adrenal response independent of its administration. In addition, unlike synthetic glucocorticoids, such as dexamethasone, $F$ feedback effects are not limited to pituitary and hypothalamic areas because it can occupy both MR and GR in limbic areas of the brain, which appear to be important for feedback mechanisms (11). In response to $\mathrm{F}$ administration, the 25-d-old animals had a brisk and rapid $F$ increase in blood, whereas the adult animals had a seemingly modest increase. Both groups of animals were given equivalent $F$ doses $(0.06 \mathrm{mg} / \mathrm{kg}$ body weight). Differences in blood volume, body composition, absorption from the peritoneum, or a combination of these may explain the differences between the two age groups. In spite of the modest $F$ increase observed in the adult, suppression of ACTH release in response to ether is effectively achieved within $15 \mathrm{~min}$. In contrast, a 2-fold increase in $\mathrm{F}$ in the 25-d-old animal results in a transient but significant $\mathrm{ACTH}$ release in response to ether that lasts $30 \mathrm{~min}$. A glucocorticoid increase of this magnitude is known to abolish ACTH release completely in the adult (11). Interestingly, the adrenal of the 25-d-old animal remains 

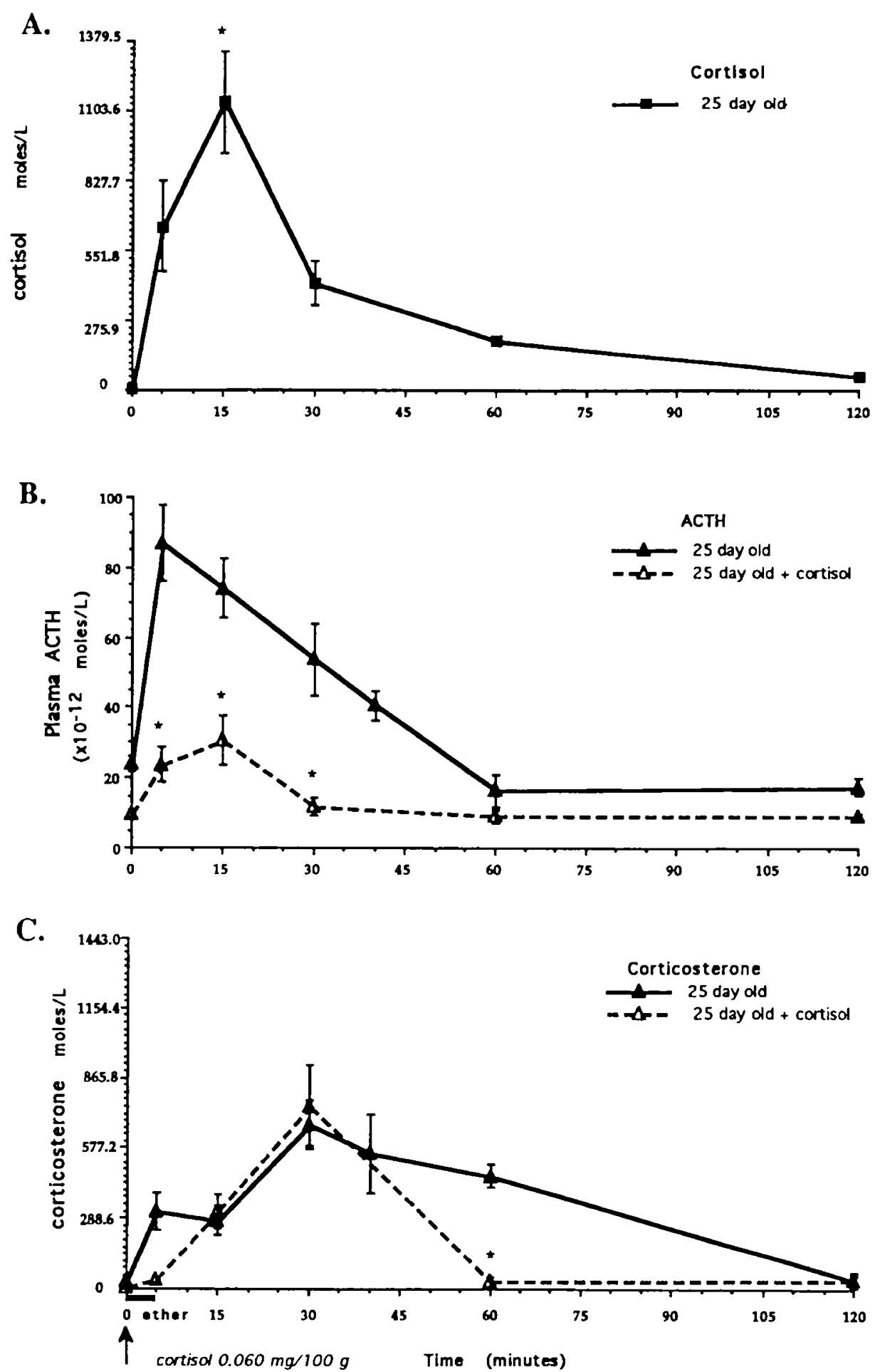

Fig. 5. The response of 25 -d-old animals treated with $0.060 \mathrm{mg} / 100 \mathrm{~g}$ body weight of $F$ intraperitoneally at the onset of a 3-min ether vapor exposure. $A$ depicts plasma $\mathrm{F}$ levels. $B$ shows the ACTH response, and $C$ the B response of animals treated with saline $(\mathbf{\Delta})$ vs $\mathrm{F}(\triangle)$. ${ }^{*}, p \leq 0.001$, cortisol treatment $v s$ ether response. One $\mu \mathrm{g} / \mathrm{dL} \mathrm{B}=28.86 \mathrm{~mol} / \mathrm{L} ; 1 \mu \mathrm{g} / \mathrm{dL}$ of $\mathrm{F}=27.59 \mathrm{~mol} / \mathrm{L}$.

responsive to the relatively low ACTH levels. Moreover, the adrenal cortex responds to the same peak as it did to the much higher levels of ACTH resulting from ether exposure. This is reminiscent of the 18-d-old animal response in which low ACTH release is coupled with a robust adrenocortical response and underscores that the immature adrenal behaves uniquely in the weanling animal. However, although the 25-d-old animal responded to ether with a prolonged $B$ response lasting $60 \mathrm{~min}$, the same animal exhibited a much shorter $B$ response (15 min) after the inhibition by $F$. We conclude that $A C T H$ suppression is achieved in the weanling animal after glucocorticoid administration. However, compared with the adult, the 25-d-old animal's ACTH suppression may require a greater rate of increase and a longer time frame of glucocorticoid exposure.

The development of a competent and fully functional LHPA axis surpasses the initial silent period described as the SHRP. Although the animal acquires the ability to activate a stress response before the weaning period, the adrenal response is far from perfect, both in the immediate response and in the magnitude of the response. The immediate response is slow, and 
although the total amount of B released by the 25-d-old rat in response to ether vapor seems equivalent to the amount released by the adult, the 25-d-old is not achieving the proper rate of increase. We propose that intrinsic developmental factors unique to the maturation of the adrenal contribute to a less efficient fast feedback mechanism in the 25-d-old animal. In addition, the supraadrenal elements in the weanling animal, i.e. pituitary, hypothalamus, and/or hippocampus, do not respond to a high rate of glucocorticoid increase. Therefore, the combination of adrenal and central elements are contributing to a "faulty" glucocorticoid turnoff. Several investigators have proposed that hippocampal GR and MR, brain serotonin, and catecholaminergic neuronal pathways converging in the hypothalamus appear to be important for the immediate inhibition of the LHPA axis. The GR and MR in the developing animal, and in particular in the 25-d-old animal, are comparable to those in the adult animal both in affinity and number $(42,43$, and unpublished observations). Therefore, it is unlikely that hippocampal GR and MR are responsible for the phenomena observed. However, serotonin and catecholaminergic circuits emerging from the hippocampus and proceeding to the hypothalamus are at the height of their development in the weanling animal. It seems possible that neuronal factors may be strongly contributing to a sluggish ACTH inhibition. Further studies are needed to clarify which neuronal factors correlate best with the establishment of a proper fast feedback response and to what extent they are independent of the appearance of a normal adrenal activation response.

Acknowledgments. The authors thank Juan F. López and M. Inés Morano for their scientific discussions and helpful critical reading of this manuscript.

\section{REFERENCES}

1. Dallman MF, Akana SF, Cascio CS, Darlington DN, Jacobson L, Levin $N$ 1987 Regulation of ACTH secretion: variations on a theme of B. Recent Prog Horm Res 43:113-173

2. Munck A. Guyre PM. Holbrook NJ 1984 Physiological functions of glucocorticoids in stress and their relation to pharmacological actions. Endocr Rev $5: 25-44$

3. Sapolsky RM. Meaney MJ 1986 Maturation of the adrenocortical stress response: neuroendocrine control mechanisms and the stress hyporesponsive period. Brain Res Rev 11:65-76

4. Dayanithi G, Antoni FA 1989 Rapid as well as delayed inhibitory effects of glucocorticoid hormones on pituitary adrenocorticotropic hormone release are mediated by type II glucocorticoid receptors and require newly synthesized messenger ribonucleic acid as well as protein. Endocrinology 125:308313

5. Sapolsky RM, Armanini MP, Packan DR, Sutton SW, Plotsky PM 1990 Glucocorticoid feedback inhibition of adrenocorticotropic hormone secretagogue release. Neuroendocrinology 51:328-336

6. Levin N, Shinsak o J, Dallman MF 1988 Corticosterone acts on the brain to inhibit adrenalectomy-induced adrenocorticotropin secretion. Endocrinology 122:694-701

7. Herman J, Schafer M, Young E. Thompson R, Douglass J, Akil H. Watson SJ 1989 Evidence for hippocampal regulation of neuroendocrine neurons of the hypothalamo-pituitary-adrenoconical axis. J Neurosci 9:3072-3077

8. Goldman L. Winget C. Hollingshead GW, Levine S 1973 Postweaning development of negative feedback in the pituitary-adrenal system of the rat. Neuroendocrinology 12:199-211

9. Walker C-D. Scribner KA. Cascio CS, Dallman MF 1991 The pituitaryadrenocortical system of neonatal rats is responsive to stress throughou development in a time-dependent and stressor specific fashion. Endocrinology 128:1385-1395

10. Smotherman WP 1983 Mother-infant interaction and the modulation of pituitary-adrenal activity in rat pups after early stimulation. Dev Physiol 16:169-176

11. Keller-Wood ME, Dallman MF 1984 Corticosteroid inhibition of ACTH secretion. Endocr Rev 5:1-23

12. Jones MT. Tiptaft EM 1977 Structure-activity relationship of various corticosteroids on the feedback control of corticotrophin secretion. Br J Pharmacol $59: 35-41$

13. Jones MT, Hillhouse EW 1976 Structure-activity relationship and mode of action of corticosteroid feedback on the secretion of corticotrophin-releasing factor (corticoliberin). J Steroid Biochem 7:1189-1202

14. Widmaier EP. Dallman MF 1983 The effects of corticotropin-releasing factor on adrenocorticotropin secretion from perifused pituitary in vitro: rapid inhibition by glucocorticoids. Endocrinology 115:2368-2374

15. Kancho M, Hiroshige T 1978 Fast, rate-sensitive corticosteroid negative feedback during stress. Am J Physiol 234:R39-R45

16. Mahnoud SN, Scaccianoce S. Scraggs PR. Nicholson SA, Gillham B. Jones MT 1984 Characteristics of corticosteroid inhibition of adrenocorticotropin release from the anterior pituitary gland of the rat. J Endocrinol 102:33-42

17. Sapolsky RM, Krey LC, McEwen BS 1986 The neuroendocrinology of stress and aging: the glucocorticoid cascade hypothesis. Endocr Rev 7:284-301

18. Sapolsky RM, Krey LC. McEwen BS 1984 Glucocorticoid-sensitive hippocampal neurons are involved in terminating the adrenocortical stress response. Proc Natl Acad Sci USA 81:6174-6177

19. Morano MI, Fstivariz. FE 1987 Chromatographic characteristics of pro-opiomelanocortin-derived peptides from the rat transplantable tumour $7315 \mathrm{a}$. J Endocrinol 112:417-425

20. Castro MG, Istivariz FE Iturriza IC 1984 The regulation of the corticomelanotrophic cell activity in aves-I. Evaluation and selection of in vitro systems for testing ACTH-releasing substances in the duck pituitary. Comp Biochem Physiol 79A:169-173

21. West CD, Mahajan DK. Chavre VY. Nabers CY'. Tyler FH 1973 Simultaneous measurement of multiple plasma steroids by radioimmunoassay demonstrating episodic secretion. J Clin Endocrinol Metab 36:123()-1236

22. Snedecor GW, Cochran WG 1982 Statistical Methods. Iowa State University Press, Ames, 1A, pp 215-237

23. Grino M. Burgunder JM, Eskay RL, Eiden LE 1989 Onset of glucocorticoid responsiveness of anterior corticotrophs during development is scheduled by corticotropin-releasing factor. Endocrinology 124:2686-2692

24. Almazan G, Lefebevre DL, Zingg HH 1989 Ontogeny of hypothalamic vasopressin, oxytosin and somatostatin gene expression. Dev Brain Res 45:6975

25. Coyle JT, Axelrod J 1972 Dopamine-hydroxylase in the rat brain: development characteristics. J Neurochem 19:449-459

26. Khachaturian H, Sladeck JR 1980 Simultancous monoamine histofluorescence and neuropeptide immunocytochemistry: III. Ontogeny of catecholamine varicosities and neurohysin neurons in the rat supraoptic and paraventicular nuclei. Peptides 1:77-95

27. Breese GR, Traylor TD 1972 Developmental characteristics of brain catecholamines and tyrosine hydroxylase in the rat: effects of 6-hydroxydopamine. $J$ Pharmacol 44:210-222

28. Papova NK, Lobacheva II 1982 Serotonin in the development of pituitaryadrenocortical response to stress. Brain Res 246:217-223

29. Lidov HGW, Molliver ME 1982 An immunohistochemical study of serotonin neuron development in the rat: ascending pathways and terminal ficlds. Brain Res Bull 8:389-430

30. Deskin R, Seidler FJ, Whitmore WL. Slothin TA 1981 Development of anoradrenergic and dopaminergic receptor systems depends on maturation of their presynaptic nerve terminals in the rat brain. J Neurochem 36:16831687

31. Pittman RN, Minneman KP. Molinoff PB 1980 Ontogeny of $\beta 1$ - and $\beta 2$ adrenergic receptors in rat cerebellum and cerchral cortex. Brain Res $188: 357-363$

32. Arai M. Widmaier EP 1991 Activation of the pituitary-adrenocortical axis in day-old rats by insulin-induced hypoglycemia. Endocrinology 129:15051512

33. Van Dorn AWV. Deane HW 1950 A morphological and cytochemical study of the postnatal development of the rat's adrenal cortex. Anat Rec 107:265281

34. Dallman MF 1984-85 Control of adrenocortical growth in vivo. Endocr Res 10:213-242

35. Greep RO, Deane HW 1949 Histological, cytochemical and physiological observations on the regeneration of the rat's adrenal gland following enucleation. Endocrinology 45:42-56

36. Leeper L., Schroeder R, Henning SJ 1988 Kinetics of circulating corticosterone in infant rats. Pediatr Res 24:595-599

37. Kamoun A 1973 Concentration et cinetique de disparition de la corticosterone en fonction de la qualite des proteines alimentaires chez le rat en croissance. Pathol Biol (Paris) 21:123-1.32

38. Koch B 1969 Fraction libre de la corticosterone plasmatique et reponse hypophyso-surrenalienne au stress durant la periode post-natale chez le rat. Horm Metab Res 1:301-308

39. Koch B, Lutz B, Mialhe C 1969 Taux plasmatique et metaholisme de la corticosterone pendant la periode post-natale chez le rat. J Physiol (Paris) $61: 142$

40. Schroeder RJ, Henning SJ 1989 Roles of plasma clearance and corticosteronebinding globulin in the developmental increase in circulating corticosterone in infant rats. Endocrinology 124:2612-2618

41. Dallman MF, Jones MT 1973 Corticosteroid feedback control of ACTH secretion: effect of stress-induced corticosterone secretion on subsequent stress responses in the rat. Endocrinology 92:1,367-1375

42. Rosenfeld P, Sutanto W, Levine S, De Kloet R 1988 Ontogeny of Type I and Type II corticosteroid receptors in the rat hippocampus. Dev Brain Res 42:113-118

43. Sarrieau A. Sharma S. Meaney MJ 1988 Postnatal development and environmental regulation of hippocampal glucocorticoid and mineralocorticoid receptors. Brain Res 471:158-162 